\title{
Analysis and Identification of Cloud Usage in Private and Public Sector in Saudi Arabia
}

\author{
Saleh M. Alturki, PhD \\ College of Computer Sciences \\ and Information Technology \\ King Faisal University, Saudi Arabia
}

\begin{abstract}
Cloud is an innovation technology of current digital environment. It provides the facility to store and transact enormous data across the world. In addition to that, it offers incredible processing power, a wide array of storage space and unbelievable speed of computation. There are many private and public organization that cannot afford such investment to store and maintain huge data base server, cloud computing is the best solution to full filling all the objectives to control massive storage. Public and private sector need to respond quickly to increasing demands from public, customer and small vendor, while coping with fixed or declining budgets and staff. Saudi is the leading economy in the Arabian Gulf region. Leading the economic positions is not easy without technological support. Adoption of new innovations should be preceded by analysis of the added value, challenges and adequacy from technological, organizational and environmental perceptions. In this stimulating digital environment, internet cloud has become a gradually pretty choice for providing services more securely, reliably, and economically. This paper briefly outlines the general framework and specific actions that can help the needs of the community, including individual person, customer, small vendors and others. Also it tries to discourse related research topics, challenges ahead and possible applications in Saudi public and private organization.
\end{abstract}

\section{Keywords}

Cloud, ICT, Public sector, Private sector, Public cloud, Private cloud, Hybrid cloud, Social cloud.

\section{INTRODUCTION}

Cloud service is an emerging technology as a new prototype for distributing computing as a service. It permits leasing of ICT capabilities whether they are infrastructure, platform, or software applications as services on subscription oriented services in a pay-as-yougo model [1][10]. The Cloud is a metaphor for the Internet, based on how it is depicted in computer network diagrams and is an abstraction for the complex infrastructure it conceals. It is a style of computing in which IT-related capabilities are provided "as a service", allowing users to access technology-enabled services from the Internet (i.e., the Cloud) without knowledge of, expertise with, or control over the technology infrastructure that supports them [4].

Cloud computing mainly is a delivery of computing as a service rather than acquiring IT products, whereby shared resources, software, and information are pro-vided to computers and other devices as a utility (like the electricity grid) over a net-work (typically the Internet) [1]. Cloud computing providers offer their services ac-cording to three fundamental models: infrastructure as a service (IaaS), platform as a service (PaaS), and software as a service (SaaS) [5].

At present Saudi Arabia deploy massive usage of cloud computing in private and public sector and educational institution as well. Saudi Arabia captivating prominent role as a massive oil producer and leads in economical in gulf region. This should be one of the reasons for establishing cloud computing environment in all public sectors of Saudi.

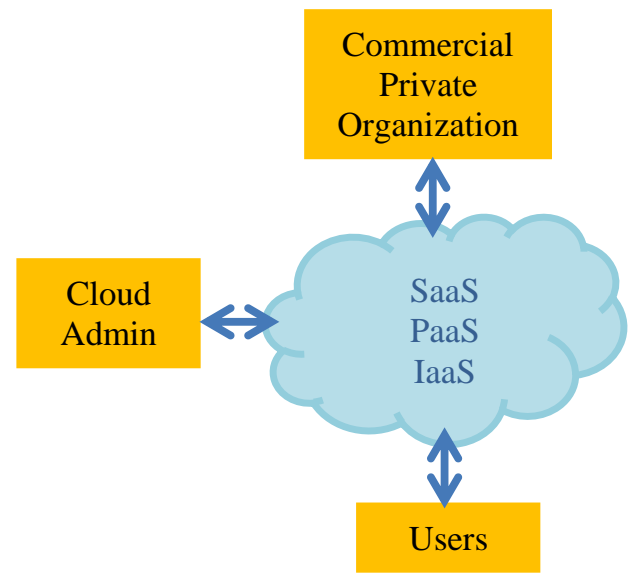

Figure 1: Simple Cloud model

Private cloud provides infrastructure to the company for individual operation. Private cloud service controlled and managed by the company. Public cloud providing service to the public individual citizen can avail the infrastructure for their own usage and getting service from the government sector. Hybrid cloud infrastructure is a combination of two or more clouds provide service for the people and small business sector. Community cloud infrastructure provides service to the particular facility to various business organizations.

The Saudi cloud infrastructure is tuned by a combination of local, regional, and global providers. Saudi Telecom and Aramco public sectors using global cloud service providers. The cloud service provider concentrating in Saudi Arabia can be broadly identified into communications service providers (STC), global software sellers, and pure-play cloud providers for the banking and other business sector. Saudi Telecom Company is among the leading role of the cloud business in Saudi Arabia and has constantly stayed increasing their ICT services contributions by controlling their data base center and establishing connectivity setup.

Saudi public and private organizations with advanced business and ICT processes that have already implemented cloud services have long been attaining the benefits of this cloud service delivery structure, including rapid utilization of ICT resources, cost savings due to optimal utilization of these 
resources, and better scalability and tractability. Many businesses are finding it tough task to invest large-scale ICT implementations and are immediately changing to public cloud service deployment models to increase access to advanced information technologies and enable them to concentrate more on their business activities. Cloud services not reached completely at regionally in Saudi Arabia comparing to developed nation such as Europe and US.

In this research study, the factors that influence the adoption of cloud storage by public and private sector were analyzed. There are many significant factors were found in this context. Generally, establishing cloud in any private sector, Public sector raised several question such as cost, quality of data connectivity, data safety and privacy etc.,

This paper is organized in the following sections: In Section II, we give a background study of cloud service used. . In Section III we describe the problems of cloud based services in private and public sector. In Section IV discussed about research methodology, in section $\mathrm{V}$ discussed about research findings. Finally in section VI we will discuss conclusion and future work

\section{LITERATURE REVIEW}

Abu Sarwar Zamani , Md. Mobin Akhtar, Sultan Ahmad (2011) authors discussed about service oriented data storage offers by the cloud environment, it has software and platforms as services, reduced information technology investment for the individual person, provides maximum flexibility, minimize total cost of companies, on demand services and many more facilities. In this research paper is a short-term survey founded on studying of cloud computing and it tries to address related research topics, challenges ahead and possible applications. The author found that there is a distinct focus on the needs of the scientific computing community. These research articles identify the answer for the following questions. The Cloud is going to happen but which services should be offered on the cloud and for whom. Thought about involvement of smaller IT companies start to offer their services on the cloud and no customer, then investment in business totally unused. The authors believe that everything eventually can move to the Cloud. The question is if users are ready for that and if it's the right move and this need must be addressed [4].

Ms. Heena Kharche Mr. Deepak Singh Chouhan (2012) there are big security issues when using cloud storage services. With the development of cloud computing, Asymmetric key Infrastructure technology has undergone a renaissance, enabling computer to computer communications. This study describes use of public key in cloud computing and provides insights into some of the challenges which cloud-based Public key systems face. One critical factor in security is cost. To limit the incentives to break the system, the cost of breaking the system should be higher or equal to the value of the information the system is protecting. The paper has discussed a prototypical to build trust in Cloud using public key Infrastructure [1].

Amin Noaman1, Fekry Fouad (2013)Cloud computing is the delivery of computing as a service rather than a product, hereby shared resources, software, and information are provided to computers and other devices and utilities. It is important that Information Technology projects in any learning organization are governed at a strategic board level and not - as before - just by the IT department. E-learning systems usually require many hardware and software resources. There are many educational institutions that cannot afford such investments, and cloud computing is the best solution. This article presents the support of E-Learning ethics with the Cloud principles and the impact on using cloud computing for e-learning solutions within international criteria. When developed, these Standards help to address cloud computing challenges in E Learning environments, including many services such as data location and recovery, security, rediscovery, availability, reliability and portability[5].

Saleh Alshomrani, and Shahzad Qamar (2013)The utilization of Information and Communication Technology (ICT) has good impact on performance of businesses. Enabling successful implementation of e-business in mind, many governments decided to use ICT in public affairs in order to implement the performance of public sector companies in the method of providing best potential information and services to people, private sector and other governments. The use of cloud based government is to help the governments in providing quick and best possible services to the citizens and businesses sectors, and to reduce the costs as in cloud based government they will not require to purchase and install the ICT equipment's on their own premises. In this paper authors analyzed cloud computing and its applications in the context of e-government

\section{PROBLEM STATEMENT}

In Saudi Arabia 100\% implementation of cloud internet in public and private sector required Special IT skilled professionals. In addition to that provisioning datacenter and managed services Increase data security and privacy. Technologically cloud environment is new concept to make relevant regulations and enforcement measures. Also, I require effective broadband quality to reach availability of service in the all parts of country. Cloud environment raises a series of significant policy issues such as privacy, anonymity, data security, government surveillance, Communications capacity, reliability etc. The expectation of government and private companies seeks data reliability and data security, because most of the cloud provider from the other country. In KSA government and private sectors will expect that the cloud provider will prevent unauthorized access of data and coding [6].

\section{METHODOLOGY}

In order to map the current state of Cloud usage and benefits in Saudi Arabia and to assess the current developments and changes after establishment of cloud services in government and private sector organization. We issued and collected 360 simple questionnaire forms with private companies and government organizations employees and public to measure the penetration of cloud service management and facility in Saudi Arabia. The questionnaire form consist current usage of cloud, services by the cloud provider, service to the customer, infrastructure facility, market development and economic growth etc.,

The survey were taken from telecom industry and private industry ICT maintenance staff, banking sector system maintenance personnel and Educational institution Information technology staff etc., This survey study was undertaken to determine how private company and public sector providing service to the customer view the use of cloud computing technology. For the identification of performance, we categorize 7 segment questionnaire's format and distribute the above mentioned personnel's. The questionnaire's format consist seven main heading and several 
sub heading. The main segments of questionnaire were as follows:-

- Upgrades and Maintenance

- Logging and Cloud Management

- Hosting Infrastructure, Backup and Disaster Recovery

- Software support management

- Performance and Benchmarking

- Architecture and Supported Platforms

- Security performance

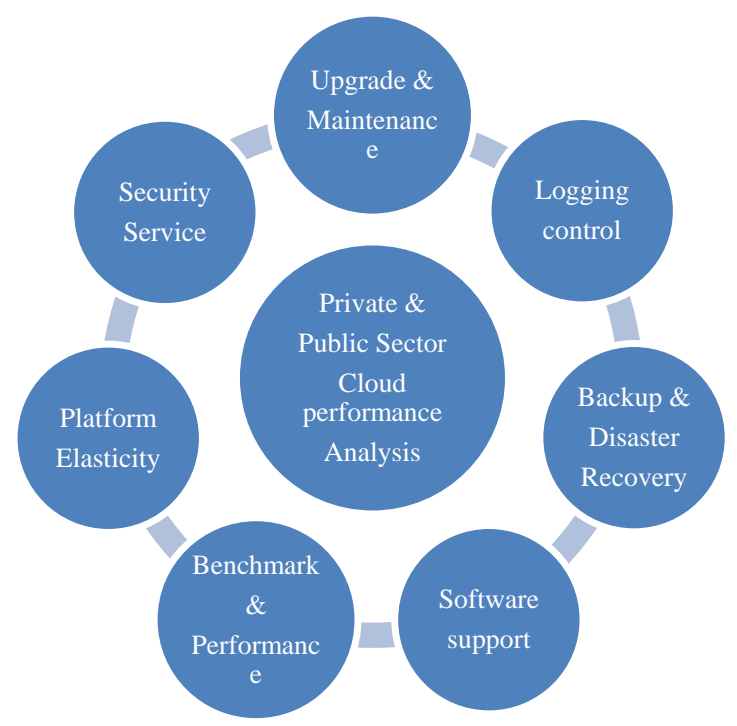

Figure 2. Cloud Survey approach methodology

The study identified the internal and external factors that can influence performance in usage and adoption of cloud computing components Cloud computing offers a variety of services that vary in importance from one company to other. Many private and public sector organizations are focused on providing enough cloud computing resources to fulfill users' requirements and data storage commitments.

\section{RESEARCH SURVEY ANALYSIS}

Cloud computing technology appears to be an excellent solution for many private and public company in Saudi Arabia that struggle with information technology complexity and cost. At the same time, cloud computing can provide excellent infrastructure to store and transmit of enormous data on the internet. Cloud computing, as observed in many commercial and governmental industry involvements, can handle many products and services that are given by traditional ICT divisions. In addition, cloud computing can offer the IT developer many different tools and options to improve projects.

\subsection{Upgrades and Maintenance}

The key concept of evolutionary innovation of cloud is the distribution of incremental extending the capabilities. Upgrading concept will keep the consumer on the spending investment to the other new technology. The survey result of the upgrade and maintenance, well-found in the given figure. The upgrade and maintenance are achieved by private company $99 \%$ and public sector $95 \%$ respectively.

Table 1. Research criteria

\begin{tabular}{|l|c|c|}
\hline Survey Features & Private in \% & Public\% \\
\hline Maintenance & 99 & 95 \\
\hline Logging & 100 & 100 \\
\hline Backup & 100 & 96 \\
\hline Software & 100 & 100 \\
\hline Performance & 100 & 94 \\
\hline Platform-support & 100 & 100 \\
\hline Security & 98 & 92 \\
\hline
\end{tabular}

\subsection{Logging and Cloud Management}

Logging and Management is identifying the events, transactions, errors, usage statistics, performance metrics, network traffic, security issues, and much more. Cloud computing management is modularized, distributed systems, accessing log data is a challenge.

\subsection{Hosting Infrastructure, Backup and Disaster Recovery}

Disaster recovery in the cloud is a moderately new perception, and similar to the many technology trends, there's a lot of excitement and deception out there, It is discussing about secure transaction and storage of data in cloud. Cloud vendor offers two authentications to recover data from disaster.

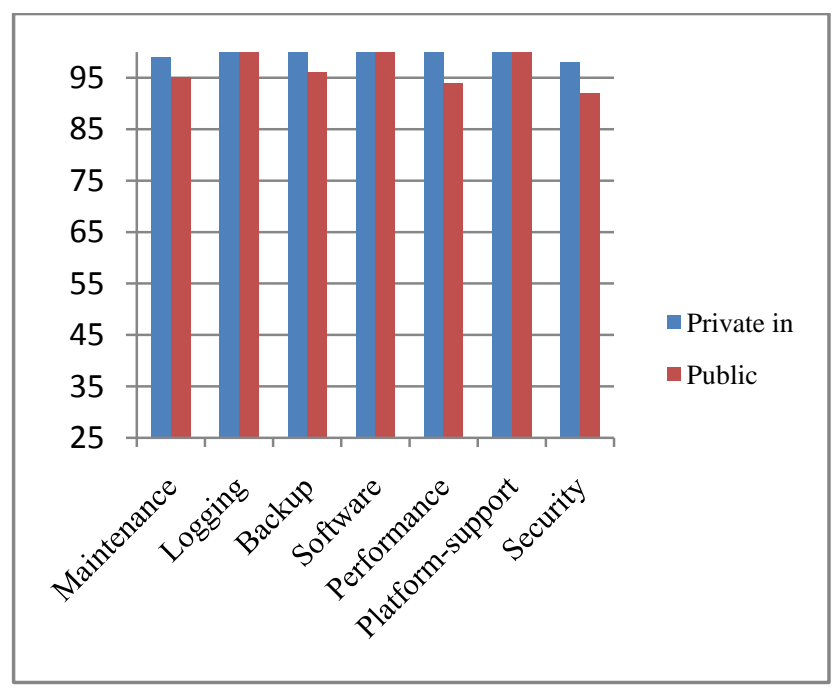

Figure 3. Cloud performance analysis graph

\subsection{Software support management}

Cloud software management is critical to supporting transaction alertness while managing risk across complex network environments. New digital technology with fast, preset provisioning of multiple type of applications. Software support reduces risk with automated cloud compliance and management 
Table 2: Research Questionnaire form

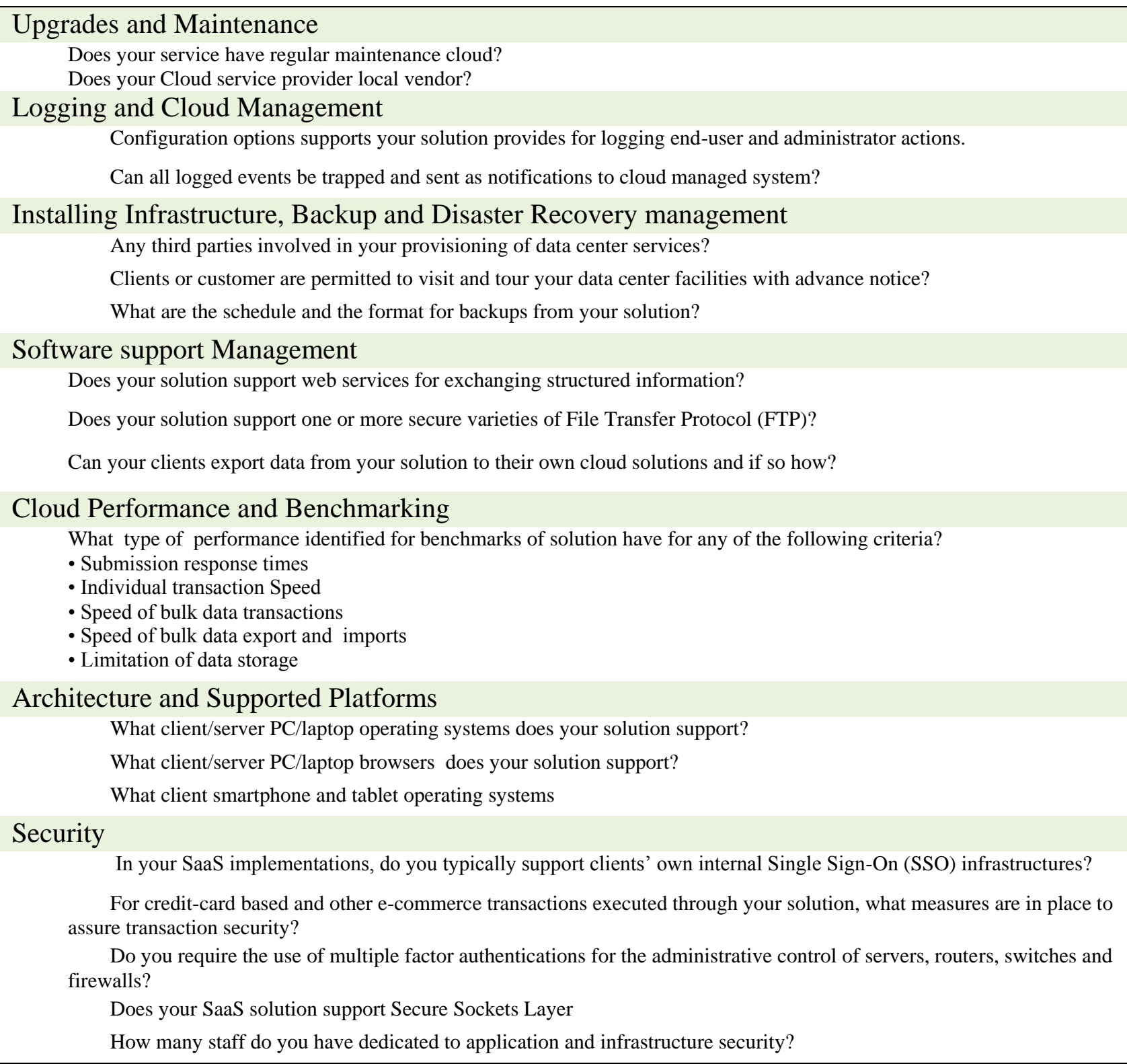

\section{RESEARCH FINDINGS}

Motivation of our research is to identifying the obstacles of private and public cloud. We are trying eliminating the remoteness of consumer, organization and cloud provider. Also, we are trying to suggest reduce IT costs, it is about transforming businesses, gaining extreme competitive advantage, interacting directly with customers in real time. Cloud adoption, too, show similar fragmentation across Saudi organizations, although security remains in the top concern to implement the cloud technology in all the industry. We found the major issues of implementing cloud services in Saudi private and public sector organizations. As per our Research survey most of the public and private company concerns about the security of cloud computing solutions.

- Organization concerns contiguous integration of cloud services.

- Customer doubtful about cloud ability to solve all kind cloud data transaction.
- Most of the companies concerns about information governance and management.

- Most of the cloud providers have lack of strategy policies.

- Public and private company ICT professionals are allowed limited access cloud computing solutions.

- Organization expecting that security of cloud service providers can meet customer compliance requirements.

- Most of the private and publication needs to simplify access to multiple cloud services for extending their business activities.

- Practice to service level benchmarks, so that cloud vendors can understand about customer needs.

- Ensure the data sets needed by cloud applications can be moved to the cloud on safely. 
- Frequent test of network level required to ensuring the data transaction.

Cloud providers are advised and provide latest security tools and schemes on the company cloud data storage.

\section{CONCLUSION}

Cloud computing is largely an evolution of Information Communication Technology that is maturing from a promising business concept to one of the fastest growing segments of the IT sector. The current study was based on the views of 360 members from private, educational institution, banking, telecom industry and public sector ICT employees. The cost and quality of data connectivity, it makes an integral part of cloud services. Cloud technologies are often perceived as key challenges as they can lead to cost of ownership and cause data transfer delay. At the Significant point of our research study concluded, most of the organization and customer worried about some valuable data resides outside the organization. Most of the private and public sector employees seek for periodical training or meeting to handle cloud data safely. As per result of research questionnaires, most of the private and public organization employees accepting that they would derive greater benefits from the use of cloud based environment. Finally, the response from the customers accepts that the service of private and public organization was positive and view cloud computing as an attractive technology option for present digital technology environment.

\section{REFERENCES}

[1] Heena Kharche, Deepak Singh Chouhan, "Building Trust In Cloud Using Public Key Infrastructure A step towards cloud trust", International Journal of Advanced Computer Science and Applications, Vol. 3, No. 3, 2012.

[2] Vinod L Desai, Dr. Nilesh K. Modi, Dr. V R Rathod, "Analytical study for applicability of Cloud Computing in Indian Environment", Int. J. of Data Modeling and Knowledge Management Vol. 1, No. 2, December 2011.

[3] Gurpreet Kaur, Manish Mahajan, "Analyzing Data Security for Cloud Computing Using Cryptographic Algorithms", Int. Journal of Engineering Research and Application, www.ijera.com ISSN : 2248-9622, Vol. 3, Issue 5, pp.782-786, Sep-Oct 2013.
[4] Abu Sarwar Zamani , Md. Mobin Akhtar and Sultan Ahmad, "Emerging Cloud Computing Paradigm", IJCSI International Journal of Computer Science Issues, Vol. 8, Issue 4, No 2, July 2011.

[5] Amin Noaman, Fekry Fouad, "Impact On Using Cloud Computing For E-Learning Solutions Within International Standards", The Clute Institute International Academic Conferences, Maui, Hawaii USA 2013.

[6] Saleh Alshomrani, and Shahzad Qamar, "Cloud Based EGovernment: Benefits and Challenges", International Journal of Multidisciplinary Sciences and Engineering, Vol.4, No.6 July 2013

[7] S. Pearson, "Privacy, Security and Trust in Cloud Computing", Edited S. Pearson, and Y. George, Springer, London, (2013), pp. 3-42.

[8] S. Lohr, "Amazon Cloud Failure Takes Down Web Sites", The New York Times., (2011), Accessed: 17/01/2017, Available at http://bits.blogs.nytimes.com/2011/04/21/amazon-cloudfailure-takes-down-web-sites/.

[9] J. Lian, D. Yen and Y. Wang, "An Exploratory Study to Understand the Critical Factors Affecting the Decision to Adopt Cloud Computing in Taiwan Hospital", International Journal of Information Management., vol. 34, no. 1, (2014), pp. 28-36.

[10] Nicholas Carr, "IT in 2018: From Turing's Machine to the Computing Cloud”, An Internet.com IT Management eBook. (C) 2008, Jupitermedia Corp.

[11] P. Gupta, A. Seetharaman and J. R. Raj, "The Usage and Adoption of Cloud Computing by Small and Medium Businesses", International Journal of Information Management, vol. 33, no. 5, (2013), pp. 861-874.

[12] N. Opitz, T. F. Langkau, N. H. Schmidt and L. M. Kolbe, "Technology Acceptance of Cloud Computing: Empirical Evidence from German IT Departments", Proceedings of the IEEE 45th Hawaii International Conference on System Science (HICSS), Maui, HI, USA, (2012) January 04-07. 